\title{
Inhibitory Effect of Essential Oils on Aspergillus ochraceus Growth and Ochratoxin A Production
}

\author{
Huijuan Hua', Fuguo Xing', Jonathan Nimal Selvaraj, Yan Wang, Yueju Zhao, Lu Zhou, Xiao Liu, \\ Yang Liu*
}

Institute of Agro-Products Processing Science and Technology, Chinese Academy of Agricultural Sciences/Key Laboratory of Agro-Products Processing, Ministry of Agriculture, Beijing, P. R. China

\begin{abstract}
Ochratoxin A (OTA) is a mycotoxin which is a common contaminant in grains during storage. Aspergillus ochraceus is the most common producer of OTA. Essential oils play a crucial role as a biocontrol in the reduction of fungal contamination. Essential oils namely natural cinnamaldehyde, cinnamon oil, synthetic cinnamaldehyde, Litsea citrate oil, citral, eugenol, peppermint, eucalyptus, anise and camphor oils, were tested for their efficacy against $A$. ochraceus growth and OTA production by fumigation and contact assays. Natural cinnamaldehyde proved to be the most effective against $A$. ochraceus when compared to other oils. Complete fungal growth inhibition was obtained at 150-250 $\mu \mathrm{L} / \mathrm{L}$ with fumigation and $250-$ $500 \mu \mathrm{L} / \mathrm{L}$ with contact assays for cinnamon oil, natural and synthetic cinnamaldehyde, $L$. citrate oil and citral. Essential oils had an impact on the ergosterol biosynthesis and OTA production. Complete inhibition of ergosterol biosynthesis was observed at $\geq 100 \mu \mathrm{g} / \mathrm{mL}$ of natural cinnamaldehyde and at $200 \mu \mathrm{g} / \mathrm{mL}$ of citral, but total inhibition was not observed at $200 \mu \mathrm{g} / \mathrm{mL}$ of eugenol. But, citral and eugenol could inhibit the OTA production at $\geq 75 \mu \mathrm{g} / \mathrm{mL}$ and $\geq 150 \mu \mathrm{g} / \mathrm{mL}$ respectively, while natural cinnamaldehyde couldn't fully inhibit OTA production at $\leq 200 \mu \mathrm{g} / \mathrm{mL}$. The inhibition of OTA by natural cinnamaldehyde is mainly due to the reduction in fungal biomass. However, citral and eugenol could significant inhibit the OTA biosynthetic pathway. Also, we observed that cinnamaldehyde was converted to cinnamic alcohol by $A$. ochraceus, suggesting that the antimicrobial activity of cinnamaldehyde was mainly attributed to its carbonyl aldehyde group. The study concludes that natural cinnamaldehyde, citral and eugenol could be potential biocontrol agents against OTA contamination in storage grains.
\end{abstract}

Citation: Hua H, Xing F, Selvaraj JN, Wang Y, Zhao Y, et al. (2014) Inhibitory Effect of Essential Oils on Aspergillus ochraceus Growth and Ochratoxin A Production. PLoS ONE 9(9): e108285. doi:10.1371/journal.pone.0108285

Editor: Richard A. Wilson, University of Nebraska-Lincoln, United States of America

Received April 21, 2014; Accepted August 19, 2014; Published September 25, 2014

Copyright: $\odot 2014$ Hua et al. This is an open-access article distributed under the terms of the Creative Commons Attribution License, which permits unrestricted use, distribution, and reproduction in any medium, provided the original author and source are credited.

Data Availability: The authors confirm that all data underlying the findings are fully available without restriction. All relevant data are within the paper.

Funding: This work was supported by grants from National Basic Research Program of China (973 program) (2013CB127805), from the National Natural Science Foundation of China (31000776), from the Ministry of Agriculture of China (Special Fund for Agro-Scientific Research in the Public Interest, 201203037). The funders had no role in study design, data collection and analysis, decision to publish, or preparation of the manuscript.

Competing Interests: The authors have declared that no competing interests exist.

* Email: liuyang01@caas.cn

9 These authors contributed equally to this work.

\section{Introduction}

Aspergillus species are frequent contaminants of low-moisture foods (water activity <0.75). Increase in metabolic activity of Aspergillus species causes the food to spoil leading to enormous economic loss. Besides, some Aspergillus species can produce toxic secondary metabolites: like aflatoxins, ochratoxins and they affect the food safety. Ochratoxins are nephrotoxic, potentially carcinogenic mycotoxins in nature [1-3]. Ochratoxin is common contaminant in food products such as cereals, coffee, wine, beer, and spices. At least 20 different ochratoxin analogs have been detected in the recent years. Ochratoxin A (OTA) is the commonly produced analogue and highly toxic [4]. OTA is mainly produced by Aspergillus ochraceus, Aspergillus carbonarius, Aspergillus westerdijkiae, Aspergillus niger, Penicillium nordicum and Penicillium verrucosum [5]. A. ochraceus is responsible for OTA contamination in rice, wheat, oats, coffee, and beverage. $A$. carbonarius and $A$. niger are responsible for OTA in grapes, raisins, and wine $[6,7]$.
As the most toxic and prevalent toxin of the ochratoxins group, OTA is highly neurotoxic, teratogenic, embryotoxic and genotoxic, immunosuppressive and immunotoxic in nature $[8,9]$. OTA was rated as potential carcinogen (group 2B) by the International Agency for Research on Cancer (IARC, 1993). European Union proposed a maximum tolerable level of $5 \mu \mathrm{g} / \mathrm{kg}$ OTA in cereal grains (European Commission, 2006), and it is similar to China.

Several strategies have been applied to prevent and control the growth of OTA producing fungi in grains. Chemical based control remains the common measure to reduce the incidence of postharvest contamination in various foods. Antifungal chemicals like benzimidazoles, aromatic hydrocarbons, and sterol biosynthesis inhibitors are often used. However, the application of them increases the risk of toxic residues in foods [10-14]. Furthermore, the use of chemical fungicides often leads to fungal resistance [15]. Therefore, a huge effort is made in the recent years to limit the use of fungicides in grains and foods. Natural antimicrobial or antifungal substances are promising to replace these synthetic fungicides. 
Essential oils (EOs) from plants have a broad spectrum of antifungal activity [16-20]. Bluma \& Etcheverry (2008) [21] screened 41 aqueous and ethanolic extracts and 22 different EOs for their antifungal effects against Aspergillus section Flavi strains and concluded that boldo, poleo, clove, anise and thyme oils could be a potential antifungal agent. In their study, EOs screened for antifungal effect was by adding them to media followed by diffusion. Boldo, poleo and clove oils could inhibit the growth of $A$. niger and $A$. carbonarius by affecting the OTA biosynthesis pathway [22]. Smaller compounds such as monoterpenes were found to highly effective when used as headspace volatiles [23]. Vapor exposure to these oils could be an effective, non-toxic biopreservatives against OTA contamination in stored grains and foods.

The objectives of our study were to: (a) examine the efficacy of different EOs like cinnamon oil, natural cinnamaldehyde, synthetic cinnamaldehyde, L. citrate oil, citral, eugenol, eucalyptus, anise, peppermint and camphor oils against $A$. ochraceus and OTA accumulation on malt extract agar (MEA) and in yeast extract sucrose (YES) broth; (b) Using contact and headspace volatile assays to analyze their antifungal effect; and (c) cinnamaldehyde transformations in YES broth with $A$. ochraceus.

\section{Materials and Methods}

\section{Essential oils}

Ten EOs were used in the present study: cinnamon oil $(85 \%$ cinnamaldehyde), natural cinnamaldehyde (95\%), synthetic cinnamaldehyde (99\%), Litsea citrate oil (85\% citral), citral (96\%), eugenol (99\% eugenol), eucalyptus (80\% cineole), anise $(92 \%$ anethole), peppermint ( $50 \%$ menthol), and camphor (55\% bomeol) oils were purchased from Jiangxi Xue Song Natural Medicinal Oil Co., Ltd, P. R. China.

\section{Fungal strain and culture conditions}

A. ochraceus 3.4412 producing OTA was gifted by Prof. Kunlun Huang (College of Food Science and Nutritional Engineering, China Agricultural University, Beijing, P. R. China) and maintained in potato dextrose agar (PDA) for 2 weeks and stored at $4^{\circ} \mathrm{C}$. The strain has previously shown to produce $1648.3 \mathrm{ng} / \mathrm{g}$ and $1536.1 \mathrm{ng} / \mathrm{mL}$ of OTA in MEA plates and YES broth, respectively.

\section{Effect of the essential oils on $A$. ochraceus growth with fumigation}

Evaluation of the antifungal activity of the EOs by fumigation was performed according to Soliman and Badeaa (2002) [24] with minor modifications. Briefly, $50 \mu \mathrm{L}$ of $10^{5}$ conidia/mL suspended in $0.01 \%$ Tween 20 was plated on $20 \mathrm{~mL}$ of MEA in a plastic Petri plate. EOs at different concentrations $(25-1500 \mu \mathrm{L} / \mathrm{L})$ was added to $10 \mathrm{~mm}$ sterile filter disks placed on cover of the Petri plate. The Petri plate was sealed by using Parafilm and incubated for 20 days at $28 \pm 1{ }^{\circ} \mathrm{C}$ (five replicates for each treatment). The colonies were measured every 2 days in two directions at right angles to each other to obtain the mean diameter. Blanks were used in triplicates.

After the incubation period, the plates showing no growth were incubated for a further 7 days under the similar temperature conditions followed by replacing new filter disk without EOs. If $A$. ochraceus growth is observed, there is a fungistatic effect, whereas if no growth occurs, the effect is fungicidal.

\section{Effect of the essential oils on $A$. ochraceus growth by contact assay}

The effect of EOs on A. ochraceus growth on MEA was studied according to Passone et al. (2012) [23] with minor modifications. MEA plates containing $20-1500 \mu \mathrm{L} / \mathrm{L}$ of EO was prepared by adding EO to $20 \mathrm{~mL}$ autoclaved medium. $50 \mu \mathrm{L}$ of $10^{5}$ conidia/ $\mathrm{mL}$ suspended in $0.01 \%$ Tween 20 was spotted on the center of each plate. Plates were sealed using Parafilm and incubated for 20 days at $28 \pm 1{ }^{\circ} \mathrm{C}$ with five replicates for each treatment. Two measurements were made at right angles to each other for each colony every 2 days to obtain mean diameter. Cultures from plates showing no growth were transferred to plates containing medium without $\mathrm{EO}$ to determine fungistatic and fungicidal effects. Blanks were used in triplicates.

\section{Determination of the minimum inhibitory concentration by contact assay}

The minimum inhibitory concentration (MIC) of EOs was determined by the broth dilution method according to YamamotoRibeiro et al. (2013) [20] with minor modifications. The EOs were diluted in $0.001 \%$ Tween-80 and tested at final concentrations of $40-40,000 \mu \mathrm{L} / \mathrm{L}$. For each essential oil, $500 \mu \mathrm{L}$ of $4 \times 10^{5}$ spores/ $\mathrm{mL}$ of $A$. ochraceus conidia was added in RPMI-1640 medium $(0.5 \mathrm{~mL})$. Tubes were incubated at $35^{\circ} \mathrm{C}$ for $72 \mathrm{~h}$ with agitation. The lowest concentration showing no visible growth was designated as MIC. Cells from the tubes showing no growth were subcultured on PDA plates to determine if the inhibition was reversible or permanent. Positive controls were performed in medium with only the cell suspension.

\section{Scanning electron microscopy (SEM)}

SEM was performed according to a modified method from Xing et al. (2014) [25]. A ochraceus was treated with natural cinnamaldehyde $(100 \mu \mathrm{L} / \mathrm{L})$, citral $(100 \mu \mathrm{L} / \mathrm{L})$ and eugenol $(250 \mu \mathrm{L} / \mathrm{L})$ on MEA medium with fumigation, respectively, Then the treated $A$. ochraceus mycelia were collected, and the fungi were mixed with formaldehyde, washed with PBS buffer, and dehydrated with gradient ethanol solutions (30, 60, 80, 90 and $100 \%$, keeping the mycelia for a longer duration in 100\%). The samples were subjected to critical point drying, subsequently, the fungal mycelia were prepared and observed under Hitachi S-750 SEM.

\section{Effect of essential oils on ergosterol biosynthesis and ochratoxin A production}

The effect of EOs on ergosterol biosynthesis and OTA production were determined according to a modified method from Kocić-Tanackov et al. (2012) [26]. Fifty milliliters of sterile YES broth (yeast extract $20 \mathrm{~g}$, sucrose $150 \mathrm{~g}, \mathrm{MgSO}_{4} \cdot 7 \mathrm{H}_{2} \mathrm{O}$ $0.5 \mathrm{~g}$, distilled water $885 \mathrm{~mL})$ were poured in flask $(150 \mathrm{~mL})$. Natural cinnamaldehyde, citral and eugenol were aseptically added to the YES broth to obtain the following concentrations: 0, $25,50,75,100,150$, or $200 \mu \mathrm{g} / \mathrm{mL}$. Three $5 \mathrm{~mm}$ diameter discs of $A$. ochraceus mycelia from PDA medium were inoculated to the YES broth., and incubated at $28^{\circ} \mathrm{C}$ for 7 days under agitation in a ZWY-2102C incubator (Zhicheng, Shanghai, China). After the incubation, YES broth containing A. ochraceus mycelia was filtered through Whatman filter No. 1 and washed with distilled water. Mycelia were used for ergosterol determination and the filters for OTA determination. Five replicates were performed for the experimental and control group. 

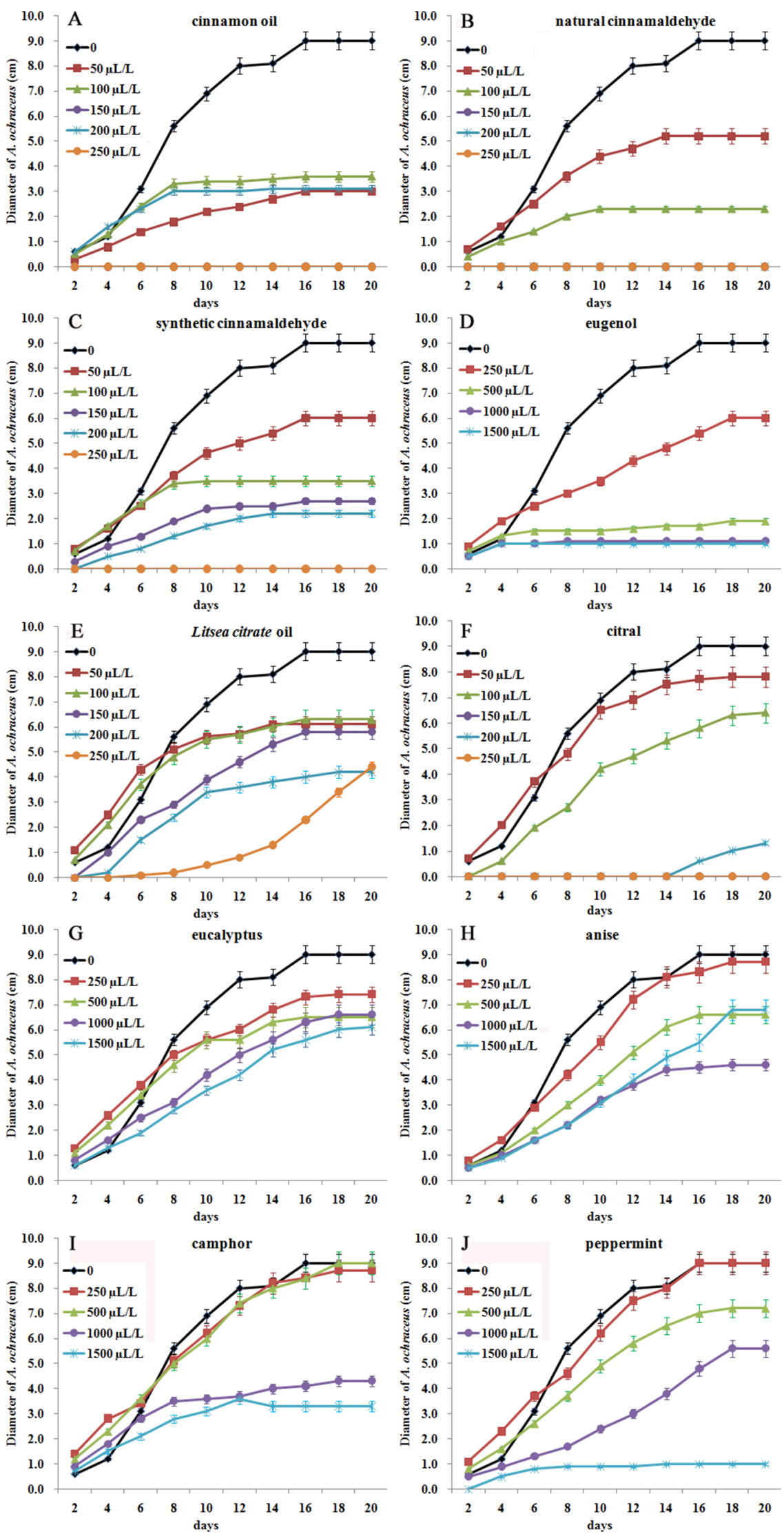

Figure 1. The effect of ten essential oils on the growth of $A$. ochraceus with fumigation. doi:10.1371/journal.pone.0108285.g001 

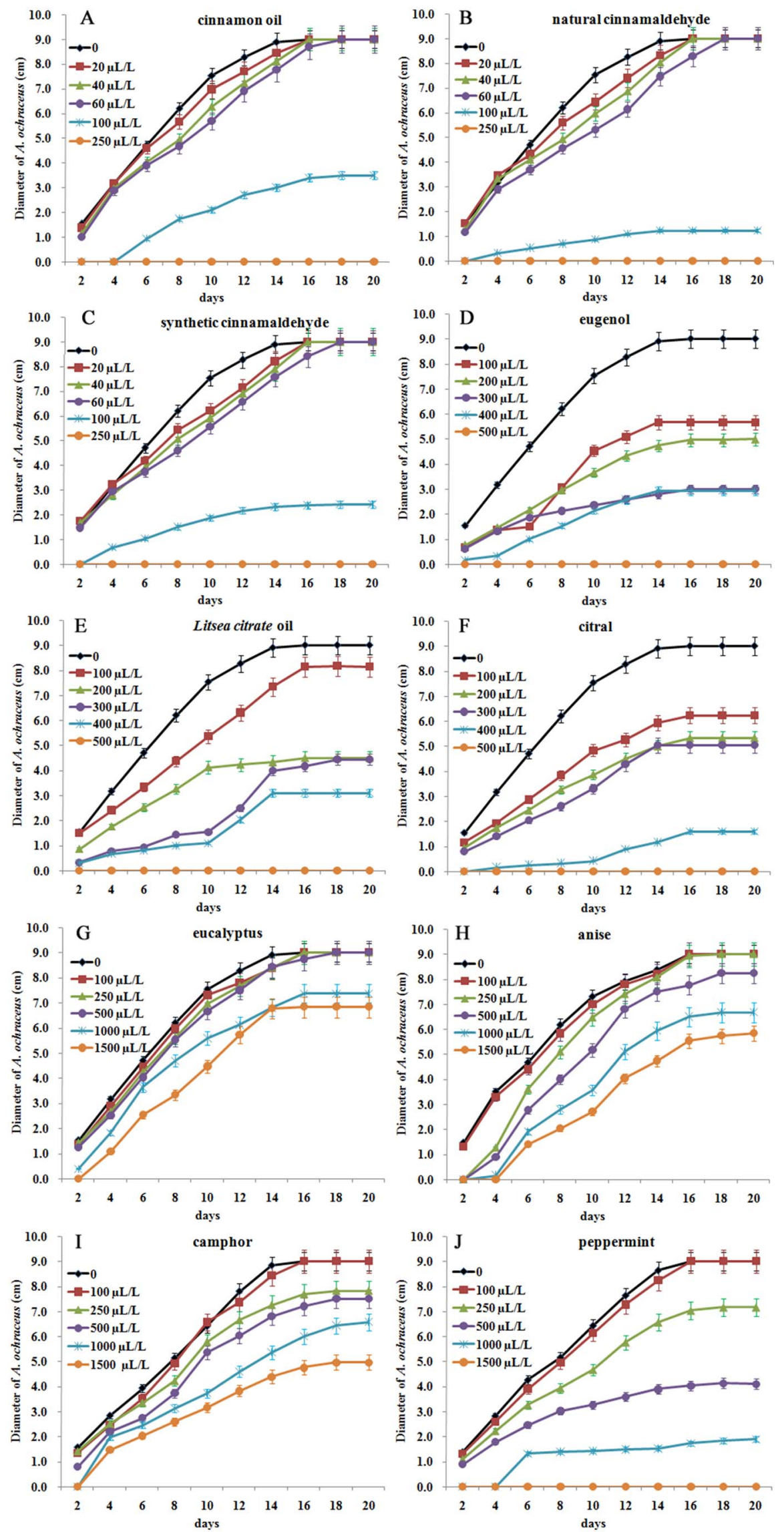

Figure 2. The effect of ten essential oils on the growth of $A$. ochraceus in contact assay. doi:10.1371/journal.pone.0108285.g002 


\section{Ergosterol and ochratoxin A standards}

Ergosterol (Sigma Chemical, St. Louis, MO, USA) solutions $(20 \mu \mathrm{g} / \mathrm{mL}$ ) were prepared in absolute ethanol PA (Merck, Germany) and $100 \mu \mathrm{g} / \mathrm{mL}$ of OTA (Sigma Chemical, St. Louis, MO, USA) was prepared in acetonitrile:water $(50: 50, \mathrm{v} / \mathrm{v})$ and stored in amber vials at $-18^{\circ} \mathrm{C}$.

\section{Ergosterol extraction and determination by high- performance liquid chromatography}

Ergosterol was extracted according to Silva, Corso, and Matheus (2010) [27] and transferred to a Falcon tube containing $20 \mathrm{~mL}$ methanol, $5 \mathrm{~mL}$ absolute ethanol $\mathrm{PA}$, and $2 \mathrm{~g}$ potassium hydroxide. The solution was stirred for $5 \mathrm{~min}$ and placed in a water bath at $70^{\circ} \mathrm{C}$ for $40 \mathrm{~min}$. After cooling at room temperature, $5 \mathrm{~mL}$ of distilled water was added and the solution was centrifuged at $1735 \times g$ for $12 \mathrm{~min}$. For final extraction, $n$-hexane was added in an equal volume to the supernatant and the organic fraction was collected in an amber glass vial and evaporated with $99.99 \%$ nitrogen flow at $60^{\circ} \mathrm{C}$. The residue obtained was stored at $-18^{\circ} \mathrm{C}$.

Ergosterol quantification was according to Yamamoto-Ribeiro et al. (2013) [20] with minor modifications. High performance liquid chromatography (HPLG) was performed with a Water 2695 (Waters Corporation, Milford, MA, USA) with an ultraviolet/ visible spectrum Waters 2475 detection system at wavelength of $282 \mathrm{~nm}$. Extract was resuspended in $1 \mathrm{~mL}$ of absolute ethanol and $100 \mu \mathrm{L}$ was injected. For the mobile phase, methanol was used at a flow rate of $1.5 \mathrm{~mL} / \mathrm{min}$. Reverse-phase HPLC separation was on a Agilent TC-C18 (Agilent, Santa Clara, USA) with a $5 \mu \mathrm{m}$ particle size column $(250 \times 4.6 \mathrm{~mm})$. Retention time was $4.6 \mathrm{~min}$ and detection limit was $0.15 \mu \mathrm{g} / \mathrm{mL}$.

\section{Ochratoxin A extraction and determination by high- performance liquid chromatography}

OTA was extracted according to Passone et al. (2012) [23] with minor modifications. Cell-free extracts $(10 \mathrm{~mL}$ mixed with $10 \mathrm{~mL}$ methanol) were stirred in shaker tubes for $1 \mathrm{~min}$, centrifuged at 14,000 rpm for $10 \mathrm{~min}$ and filtered (Titan 2 HPLC Filter Green; $17 \mathrm{~mm}$ and $0.45 \mu \mathrm{m})$. The eluate was evaporated to dryness with $99.99 \%$ nitrogen flow at $60^{\circ} \mathrm{C}$. The residue was redissolved in mobile phase (acetonitrile/water/acetic acid, 99:99:2) and the extract was injected into a tube or stored at $-18^{\circ} \mathrm{C}$.

OTA production was detected and quantified by the methodology proposed by Scudamore and MacDonld (1998) [28] with minor modifications. Reversed phase HPLC with a Waters 2475 fluorescence detection ( $\lambda$ exc $330 \mathrm{~nm}$; $\lambda$ em $460 \mathrm{~nm}$ ) was applied. Agilent TC-C18 column $(250 \times 4.6 \mathrm{~mm}, 5 \mu \mathrm{m}$ particle size $)$ was used. The mobile phase (acetonitrile/water/acetic acid, 99:99:2) was pumped at $1.0 \mathrm{~mL} / \mathrm{min}$. Injection volume was $50 \mu \mathrm{L}$ and retention time was around $6 \mathrm{~min}$. Standard curves were constructed with 5 to $100 \mathrm{ng} / \mathrm{g}$ OTA (Sigma Chemical, St. Louis, MO, USA). Toxin was quantified by correlating peak areas of sample extracts and standard curves. Mean recovery was calculated by spiking with MEA at 5 to $100 \mathrm{ng} / \mathrm{g}$ and was estimated at $89.2 \pm 9.7 \%$. The lowest detection limit was $1 \mathrm{ng} / \mathrm{g}$.

\section{Cinnamaldehyde determination by high-performance liquid chromatography}

The variations in concentrations of cinnamaldehyde and its possible metabolite cinnamic alcohol in YES broth with $A$. ochraceus (treatment) were determined by RP-HPLC analysis. YES broth containing $100 \mu \mathrm{g} / \mathrm{mL}$ of cinnamaldehyde was inoculated with $A$. ochraceus and incubated at $28^{\circ} \mathrm{C}$ with shaking at $180 \mathrm{rpm}$. YES broth without fungi inoculation by with cinnamaldehyde was the negative control and YES broth with fungi inoculation by without cinnamaldehyde was the positive control. Samples of $10 \mathrm{~mL}$ were collected at 0, 2, 4, 8, 12, 24, 48, 72 , and $96 \mathrm{~h}$ and centrifuged at $10,000 \times \mathrm{g}$ for $10 \mathrm{~min}$ at $4^{\circ} \mathrm{C}$. Cell pellets were resuspended in methanol (Fisher) and sonicated for 15 min in a Bransonic bath (5510; Branson, Grass Valley, CA). The suspension was filtered through $0.2 \mu \mathrm{m}$ nylon syringe filter units (Fisher) and analyzed for HPLC. Supernatant were mixed with $10 \mathrm{~mL}$ ethyl acetate (Sigma-Aldrich) to avoid interference by materials of YES broth in HPLC detection. The mixture was mixed on vortex for $3 \mathrm{~min}$. After a 3 min rest, the clear ethyl acetate phase at the top was collected and the procedure was repeated twice. Ethyl acetate extracts from negative controls were not centrifuged. Pooled ethyl acetate extracts from each $10 \mathrm{~mL}$ sample were evaporated using a rotary evaporator (Yarong, SY2000; Shanghai, China), and the residue was dissolved in

Table 1. MICs of the essential oils against $A$. ochraceus $^{a}$.

\begin{tabular}{|c|c|c|}
\hline Essential oils & MIC ( $\mu \mathrm{L} / \mathrm{L})$ & $\begin{array}{l}\text { Determine if the inhibition } \\
\text { was reversible or permanent }\end{array}$ \\
\hline Cinnamon oil (85\% cinnamaldehyde) & 500 & Permanent (Without visible growth occurred) \\
\hline Natural cinnamaldehyde (95\%) & 500 & Permanent \\
\hline Synthetic cinnamaldehyde (99\%) & 500 & Permanent \\
\hline Cinnamic alcohol (99\%) & 700 & Permanent \\
\hline Litsea citrate oil ( $85 \%$ citral) & 800 & permanent \\
\hline Citral (99\%) & 700 & Permanent \\
\hline Eugenol (99\%) & 600 & $600-4000$, reversible (visible growth occurred) $\geq 4000$, permanent \\
\hline Peppermint (50\% methol) & 2000 & $2000-40000$, reversible $\geq 40000$, permanent \\
\hline Eucalyptus ( $80 \%$ cineole) & $>40000$ & $>40000$, permanent \\
\hline Anise (92\% anethole) & $>40000$ & Reversible \\
\hline Camphor (55\% bomeol) & $>40000$ & Reversible \\
\hline
\end{tabular}

${ }^{a}$ Results are shown as minimum inhibitory concentrations (expressed as $\mu \mathrm{L}$ of essential oils added per $\mathrm{L}$ of liquid medium)

Reversible: visible growth occurred after subculturing on potato dextrose agar plates;

Permanent: without visible growth occurred after subculturing on potato dextrose agar plates.

doi:10.1371/journal.pone.0108285.t001 


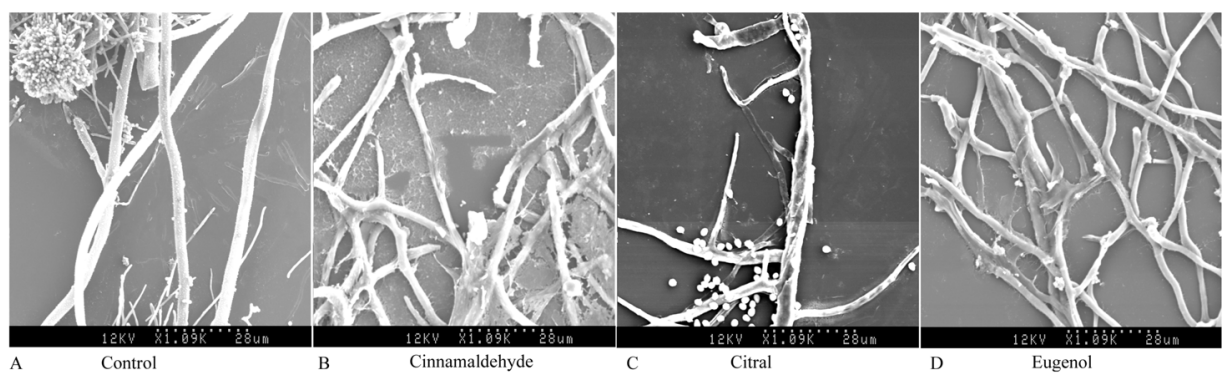

Figure 3. SEM for the nonfumigated and fumigated mycelia. A. Fumigated with $100 \mu \mathrm{L} / \mathrm{L}$ of natural cinnamaldehyde; $B$. Fumigated with $100 \mu \mathrm{L} / \mathrm{L}$ of citral; C. Fumigated with $250 \mu \mathrm{L} / \mathrm{L}$ of eugenol. doi:10.1371/journal.pone.0108285.g003

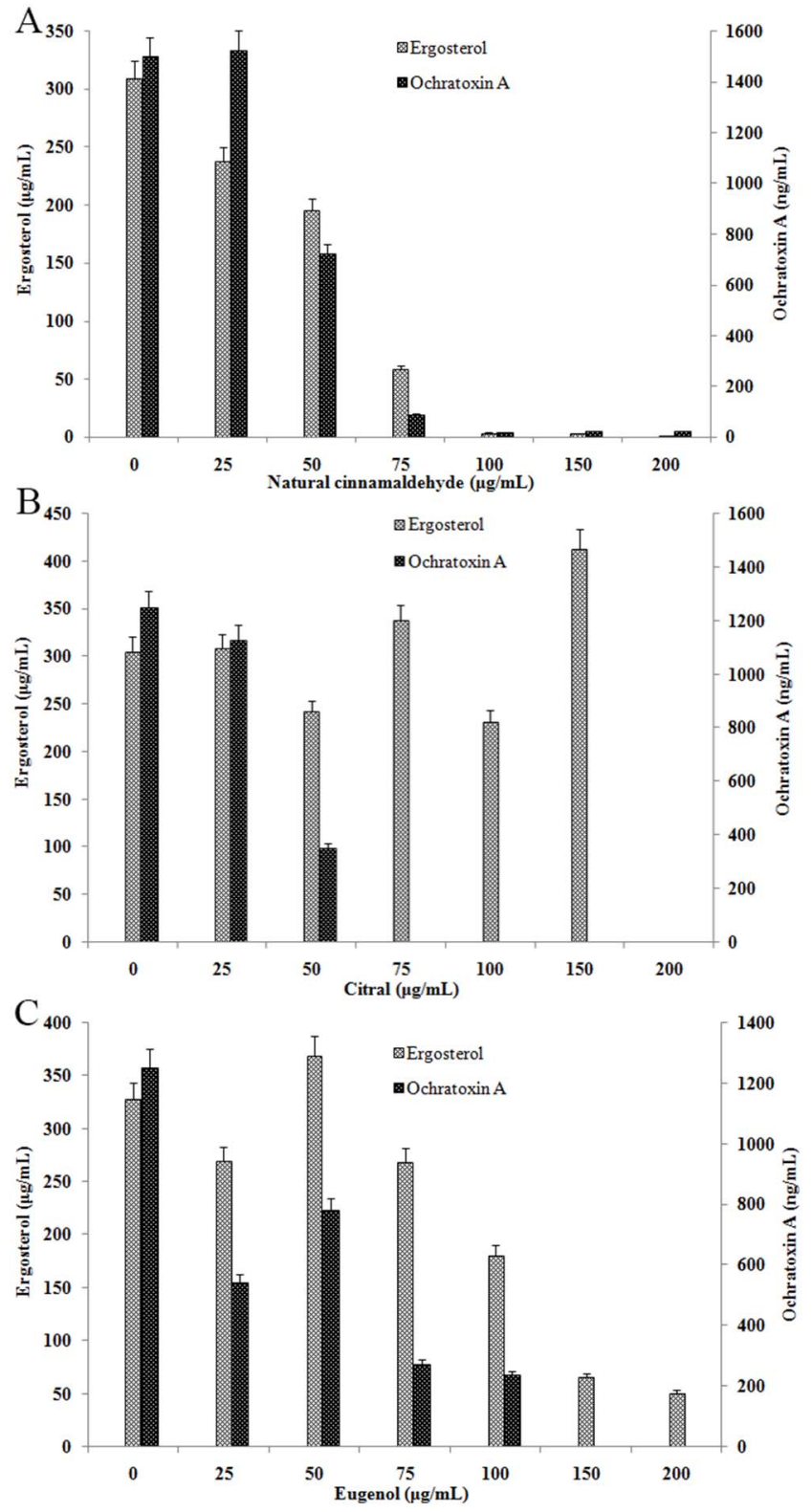

Figure 4. Effect of natural cinnamaldehyde (A), citral (B) and eugenol (C) on ergosterol biosynthesis and OTA production from $A$. ochraceus determined by HPLC. The experiment was conducted during 5 days of incubation under agitation at $28^{\circ} \mathrm{C}(\mathrm{n}=4)$. doi:10.1371/journal.pone.0108285.g004
$20 \mathrm{~mL}$ methanol. The solution was further diluted in methanol if necessary, filtered through a $0.2 \mu \mathrm{m}$ nylon syringe filter unit, and immediately used for HPLC analysis. Extracts from duplicate supernatants and corresponding cell pellets were analyzed separately.

Analysis used a Waters 2695 reversed-phase HPLC with a Waters $2487 \mathrm{UV}$ detector at $280 \mathrm{~nm}$ and empower system controller. Data were processed using Waters LC-module 1 millennium software, version 32. A reverse-phase Agilent TC-C18 column was used. The mobile phases used for separation were: A, $1 \%$ acetic acid in methanol; and $\mathrm{B}, 1 \%$ acetic acid in water. A gradient flow of mobile phases $(0$ to $10 \mathrm{~min}$ at $15 \% \mathrm{~A}, 85 \% \mathrm{~B} ; 10$ to $13 \mathrm{~min}$ at $50 \% \mathrm{~A}, 50 \% \mathrm{~B} ; 13$ to $16 \mathrm{~min}$ at $60 \% \mathrm{~A}, 40 \% \mathrm{~B} ; 16$ to $24 \mathrm{~min}$ at $65 \% \mathrm{~A}, 35 \% \mathrm{~B}$ and 24 to $40 \mathrm{~min}$ at $15 \% \mathrm{~A}, 85 \% \mathrm{~B}$ ) at $1 \mathrm{~mL} / \mathrm{min}$ was used. Retention times and standard curves for cinnamaldehyde and cinnamic alcohol were obtained by analyzing $10 \mu \mathrm{L}$ filtered standard solution $(0.5$ to $50 \mu \mathrm{g} / \mathrm{mL})$ of each compound. Curve linearity and correlation coefficients were calculated from peak areas at each standard concentration. Ten $\mu \mathrm{L}$ extract from treatment samples or positive or negative controls was injected. Methanol extracts of cells were injected separately at the same level with supernatants and final concentrations of cinnamaldehyde or cinnamic alcohol were obtained by combining values for cell extracts and extracts from corresponding supernatants.

\section{Statistical analyses}

All the experiments results were evaluated using analysis of variance (ANOVA) for multiple comparisons followed by the Turkey test. Differences were considered significant at $p<0.05$. The growth of fungal cultures with different concentrations of the EOs was compared with growth of a control with no EO.

\section{Results}

\section{Inhibitory effect of ten essential oils on A. ochraceus} growth with fumigation

Cinnamon oil, natural cinnamaldehyde, synthetic cinnamaldehyde, L. citrate oil and citral significantly inhibited the growth of A. ochraceus at $50-250 \mu \mathrm{L}$ per liter MEA medium $(P<0.01)$. Natural cinnamaldehyde proved to be the most effective against $A$. ochraceus, followed by cinnamon oil, synthetic cinnamaldehyde, citral, L. citrate oil, eugenol, peppermint, anise, eucalyptus and camphor oils (Fig. 1). The inhibitory effect increased proportionally with concentration and was also affected by treatment duration. A. ochraceus growth was completely inhibited with natural cinnamaldehyde $(95 \%)$ at $150 \mu \mathrm{L} / \mathrm{L}$, cinnamon oil $(85 \%$ cinnamaldehyde) at $250 \mu \mathrm{L} / \mathrm{L}$, synthetic cinnamaldehyde (99\%) at $250 \mu \mathrm{L} / \mathrm{L}$, citral (96\%) at $250 \mu \mathrm{L} / \mathrm{L}$. After 20 days incubation, the 

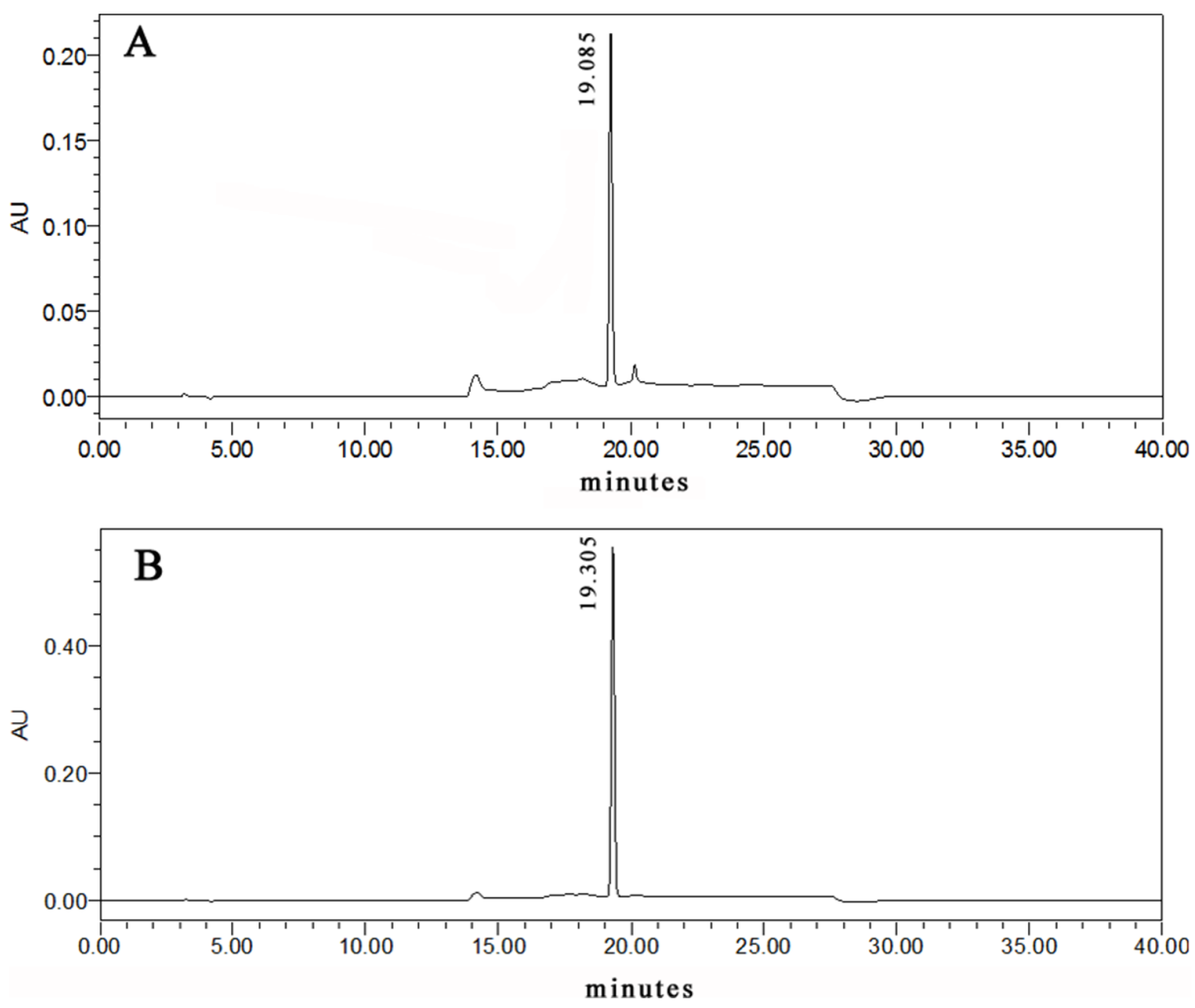

Figure 5. RP-HPLC detection of cinnamaldehyde of $50 \mathrm{mg} / \mathrm{L}$ (A) and cinnamic alcohol of $50 \mathrm{mg} / \mathrm{L}$ (B). doi:10.1371/journal.pone.0108285.g005

plates showing no growth were incubated for a further 7 days after removal of EOs, and no visible growth of $A$. ochraceus mycelia was observed. These results suggested a fungistatic effect of natural cinnamaldehyde, cinnamon oil, synthetic cinnamaldehyde and citral at lower concentrations and a fungicidal effect at higher concentrations.

Eugenol, peppermint, eucalyptus, anise and camphor oils did not completely inhibit $A$. ochraceus growth at $250-1500 \mu \mathrm{L} / \mathrm{L}$. The diameters of $A$. ochraceus colonies treated with 1000 and
$1500 \mu \mathrm{L} / \mathrm{L}$ eugenol did not increase from $1.0 \pm 0.06 \mathrm{~cm}$ from 4 to 20 days. Diameters of colonies treated with $1500 \mu \mathrm{L} / \mathrm{L}$ peppermint oil did not change from $1.0 \pm 0.07 \mathrm{~cm}$ from 14 to 20 days.

Inhibitory effect of ten essential oils on $A$. ochraceus growth with contact assay

Treatment with cinnamon oil, natural cinnamaldehyde, synthetic cinnamaldehyde, L. citrate oil, citral and eugenol significantly inhibited $A$. ochraceus growth at $100-500 \mu \mathrm{L} / \mathrm{L}$ on MEA

Table 2. Conversion of cinnamaldehyde to cinnamic alcohol by A. ochraceus* in YES.

\begin{tabular}{|c|c|c|c|c|c|c|}
\hline \multirow{2}{*}{$\begin{array}{l}\text { Treatment } \\
\text { Concentration }\end{array}$} & \multicolumn{2}{|c|}{$\begin{array}{l}\text { YES plus cinnamaldehyde, uninoculated } \\
\text { (negative control) }\end{array}$} & \multicolumn{2}{|c|}{$\begin{array}{l}\text { YES plus } A \text {. ochracesus plus } \\
\text { cinnamaldehyde, inoculated (treatment) }\end{array}$} & \multicolumn{2}{|c|}{$\begin{array}{l}\text { YES plus } A \text {. ochraceus } \\
\text { (positive control) }\end{array}$} \\
\hline & $\begin{array}{l}\text { Cinnamaldehyde } \\
(\mu \mathrm{g} / \mathrm{mL})\end{array}$ & $\begin{array}{l}\text { Cinnamic } \\
\text { alcohol } \\
(\mu \mathrm{g} / \mathrm{mL})\end{array}$ & $\begin{array}{l}\text { Cinnamaldehyde } \\
(\mu \mathrm{g} / \mathrm{mL})\end{array}$ & $\begin{array}{l}\text { Cinnamic alcohol } \\
(\mu \mathrm{g} / \mathrm{mL})\end{array}$ & $\begin{array}{l}\text { Cinnamaldehyde } \\
(\mu \mathrm{g} / \mathrm{mL})\end{array}$ & $\begin{array}{l}\text { Cinnamic } \\
\text { alcohol } \\
(\mu \mathrm{g} / \mathrm{mL})\end{array}$ \\
\hline $0 \mathrm{~h}$ & $64.56 \pm 4.26^{\mathrm{a}}$ & ND & $64.83 \pm 5.33^{\mathrm{a}}$ & ND & ND & ND \\
\hline $2 \mathrm{~h}$ & $64.13 \pm 3.21^{a}$ & ND & $62.54 \pm 4.26^{\mathrm{a}}$ & ND & ND & ND \\
\hline $4 \mathrm{~h}$ & $63.41 \pm 4.65^{a}$ & ND & $24.17 \pm 1.30^{\mathrm{b}}$ & $36.83 \pm 1.21^{a}$ & ND & ND \\
\hline $8 \mathrm{~h}$ & $62.84 \pm 5.11^{\mathrm{a}}$ & ND & $3.41 \pm 0.34^{c}$ & $55.23 \pm 2.13^{b}$ & ND & ND \\
\hline $12 \mathrm{~h}$ & $62.25 \pm 4.32^{a}$ & ND & ND & $55.52 \pm 0.27^{b}$ & ND & ND \\
\hline $24 \mathrm{~h}$ & $62.14 \pm 4.21^{\mathrm{a}}$ & ND & ND & $37.33 \pm 6.61^{c}$ & ND & ND \\
\hline $48 \mathrm{~h}$ & $61.71 \pm 2.26^{\mathrm{ab}}$ & ND & ND & $14.82 \pm 2.48^{\mathrm{d}}$ & ND & ND \\
\hline $72 \mathrm{~h}$ & $58.85 \pm 2.89^{b}$ & ND & ND & $3.12 \pm 0.39^{e}$ & ND & ND \\
\hline $96 \mathrm{~h}$ & $55.58 \pm 8.37^{c}$ & ND & ND & ND & ND & ND \\
\hline
\end{tabular}

*ND, not detected. Different superscript lowercase letters in each column indicate a significant difference $(P<0.05)$

doi:10.1371/journal.pone.0108285.t002 
medium $(P<0.01)$. Treatment with peppermint oil significantly inhibited $A$. ochraceus growth at $500-1500 \mu \mathrm{L} / \mathrm{L} \quad(P<0.01)$. However, eucalyptus, anise and camphor oils showed mild inhibition on $A$. ochraceus growth at 100-1500 $\mu \mathrm{L} / \mathrm{L}$. Natural cinnamaldehyde was highly effective against $A$. ochraceus, followed by synthetic cinnamaldehyde, cinnamon oil, citral, $L$. citrate oil, eugenol and peppermint oil (Fig. 2).

$A$. ochraceus growth was completely inhibited with natural cinnamaldehyde, synthetic cinnamaldehyde and cinnamon oil at $250 \mu \mathrm{L} / \mathrm{L}$. For a complete antifungal effect, $500 \mu \mathrm{L} / \mathrm{L}$ of citral, $L$. citrate oil and eugenol were essential. At $1500 \mu \mathrm{L} / \mathrm{L}$, peppermint oil completely inhibited the growth of $A$. ochraceus. However, eucalyptus, anise and camphor oils did not show complete inhibition at $\leq 1500 \mu \mathrm{L} / \mathrm{L}$.

\section{MIC determined by contact assay}

For A. ochraceus, the MIC of cinnamon oil (85\%), natural cinnamaldehyde (95\%) and synthetic cinnamaldehyde (99\%) were $500 \mu \mathrm{L} / \mathrm{L}$; those of L. citrate oil (85\%) and citral $(99 \%)$ were 800 and $700 \mu \mathrm{L} / \mathrm{L}$, respectively (Table 1 ). Cells from the tubes of the five EOs at $\geq 500 \mu \mathrm{L} / \mathrm{L}$ were subcultured on MEA plates and no visible growth was observed, suggesting a permanent growth inhibition. The MIC of eugenol (99\%) was $600 \mu \mathrm{L} / \mathrm{L}$ which was lower than the MIC of citral (99\%), however inhibition by eugenol at $600-4000 \mu \mathrm{L} / \mathrm{L}$ was reversible. Eucalyptus, anise and camphor oils did not completely inhibit the growth of $A$. ochraceus at $\leq$ $40000 \mu \mathrm{L} / \mathrm{L}$.

\section{Scanning electron microscopy (SEM)}

Morphological changes which occurred in the hyphae and conidiophores of $A$. ochraceus due to growing the fungus in MEA medium fumigated with $100 \mu \mathrm{L} / \mathrm{L}$ of natural cinnamaldehyde, $100 \mu \mathrm{L} / \mathrm{L}$ of citral and $250 \mu \mathrm{L} / \mathrm{L}$ of eugenol are shown in Fig. 3A-D. The growing nonfumigated healthy mycelia showed a normal morphology with linear, regular, homogenous and rough cell wall hyphae (Fig. 3A). The growing apexes of the hyphae were tapered with a smooth surface. However, this morphology underwent alterations following fumigation of the culture medium with natural cinnamaldehyde, citral and eugenol. The mycelia showed evident modifications in both apical regions and throughout the length of the hyphae. These hyphae were disrupted (Fig. 3B, D) and the apical regions of the haphae were modified and abnormal with rough surfaces (Fig. 3B, D). The hyphae became slender, shrank and winding and evident craters appeared on the cell wall (Fig. 3C). The conidiophores and vesicles were disrupted, and then the conidia were dispersed in disorder (Fig. 3C).

\section{Effect of three essential oils on ergosterol biosynthesis and OTA production}

Natural cinnamaldehyde at $25-50 \mu \mathrm{g} / \mathrm{mL}$ caused a mild reduction in ergosterol production and significantly inhibited ergosterol production in $A$. ochraceus at $75-200 \mu \mathrm{g} / \mathrm{mL}$, with inhibition ranging from $80 \%$ to $100 \%$. Natural cinnamaldehyde significantly inhibited production of OTA by A. ochraceus at lower concentrations $(50-75 \mu \mathrm{g} / \mathrm{mL})$ and almost completely inhibited production at higher concentrations (100-200 $\mathrm{g} / \mathrm{mL})$ (Fig. 4A). Thus, cinnamaldehyde-induced ergosterol inhibition correlated with a reduction in OTA production. The decrease in OTA production was proportional to the decrease in fungal biomass. A similar result was found by Yamamoto-Ribeiro et al. (2013) [20]. Other studies demonstrated that EOs and compounds, limonene and thymol, inhibit fumonisin production by $F$. verticillioides $[29,30]$.

Citral at $25-150 \mu \mathrm{g} / \mathrm{mL}$ did not inhibit ergosterol biosynthesis and completely inhibited ergosterol production in A. ochraceus at $200 \mu \mathrm{g} / \mathrm{mL}$ (Fig. 4B). The significant oscillations were observed in ergosterol biosynthesis. Ergosterol biosynthesis was significantly induced by citral at $150 \mu \mathrm{g} / \mathrm{mL}$. However, citral at $50 \mu \mathrm{g} / \mathrm{mL}$ significantly inhibited the OTA production and complete inhibition in OTA production was observed at $75-200 \mu \mathrm{g} / \mathrm{mL}$.

Eugenol at $25-75 \mu \mathrm{g} / \mathrm{mL}$ caused oscillations in ergosterol production in $A$. ochraceus and effectively inhibited ergosterol production at $100-200 \mu \mathrm{g} / \mathrm{mL}$, with inhibition ranging from $45 \%$ to $85 \%$ (Fig. 4C). This oscillation was reflected by an increase in ergosterol biosynthesis of $A$. ochraceus at $50 \mu \mathrm{g} / \mathrm{mL}$ eugenol compared with the control and significant inhibition at higher concentrations.

\section{Conversion of cinnamaldehyde by $A$. ochraceus}

The changes in concentrations of cinnamaldehyde and its possible metabolite, cinnamic alcohol, in YES with A. ochraceus (treatment) and without fungal inoculation but with cinnamaldehyde (negative control) were monitored by RP-HPLC analysis (Fig. 5). The concentration of cinnamaldehyde before incubation at $28^{\circ} \mathrm{C}(0 \mathrm{~h})$ was $64.56 \pm 4.26 \mathrm{mg} / \mathrm{L}$ with the negative controls and $64.83 \pm 5.33 \mathrm{mg} / \mathrm{L}$ with the treatment samples (Table 2). The result showed that only about $64.83 \%$ of the cinnamaldehyde added $(100 \mathrm{mg} / \mathrm{L})$ was extracted using ethyl acetate. After $2 \mathrm{~h}$ the concentration of cinnamaldehyde was stable in both the negative controls and treatment cultures. After $4 \mathrm{~h}$ the concentration of cinnamaldehyde decreased by $40 \mathrm{mg} / \mathrm{L}$ in treatment cultures, while it remained stable in the negative control during the tested time. However, with $A$. ochraceus, the concentration of cinnamaldehyde decreased to $\leq 4 \mathrm{mg} / \mathrm{L}$ at $8 \mathrm{~h}$ and was undetected at $12 \mathrm{~h}$. The concentration of cinnamic alcohol was detected at $4 \mathrm{~h}$ and increased to about $55 \mathrm{mg} / \mathrm{L}$ at $8-12 \mathrm{~h}$, then decreased to approximate $3 \mathrm{mg} / \mathrm{L}$ at $72 \mathrm{~h}$ and undetected at $96 \mathrm{~h}$. However, the concentration of cinnamic alcohol was undetectable in the positive control during the tested time. Since cinnamic alcohol was detected at 4-72 $\mathrm{h}$ in treatment samples, its MIC was determined and found to be $700 \mathrm{mg} / \mathrm{L}$ and higher than that of cinnamaldehyde.

\section{Discussion}

The 10 oils analyzed showed dose-dependent antifungal activity against $A$. ochraceus at the concentrations tested. This finding was consistent with the results obtained by Passone et al. (2012) [23] who reported that boldo (Pёumus boldus Mol.), poleo (Lippia turbinate var. Integrifolia [Griseb.]), clove (Syzygium aromaticum L.), anise (Pimpinella anisum) and thyme (Thymus vulgaris) EOs were effective non-toxic biopreservatives against Aspergillus section Nigri growth and OTA contamination in vitro. Boldo EO showed the greatest effect on fungal isolates with significant reductions at 1000 and $2000 \mu \mathrm{L} / \mathrm{L}$ and total growth inhibition at $3000 \mu \mathrm{L} / \mathrm{L}$. Matricaria chamomilla $\mathrm{L}$. oil was a potent inhibitor of $A$. niger growth in vitro with a growth inhibition at oil concentration of $15.62 \mu \mathrm{g} / \mathrm{mL}(\sim 7.5 \%)$ and reached a maximum of $\sim 92.5 \%$ at the final concentration of $1000 \mu \mathrm{g} / \mathrm{mL}$ [31].

Although the concentrations of oils tested in this study were not the same, the headspace volatile assays showed greater inhibition than the contact assays with the exception of eugenol and peppermint oil. Complete growth inhibition of $A$. ochraceus was verified at $150-250 \mu \mathrm{L} / \mathrm{L}$ by headspace volatile assays and 250 $500 \mu \mathrm{L} / \mathrm{L}$ in the contact assays for cinnamon oil, natural 
cinnamaldehyde, synthetic cinnamaldehyde, L. citrate oil and citral. In contrast, Passone et al. (2012) [23] studies showed that boldo, poleo and clove essential oils have higher inhibition effect in contact assays than headspace volatile assays. Complete growth inhibition was observed at $\geq 1500 \mu \mathrm{L} / \mathrm{L}$ for boldo, poleo and clove oils in contact assays and $\geq 2000 \mu \mathrm{L} / \mathrm{L}$ for boldo in headspace volatile assays, while full fungal growth was not observed with $3000 \mu \mathrm{L} / \mathrm{L}$ of poleo and $5000 \mu \mathrm{L} / \mathrm{L}$ of clove oils. These results showed that both assays are necessary to evaluate the inhibitory effects of essential oils. Ergosterol has hormonal and structural effects in fungal cells and is responsible for regulating the flow and activity of membrane-bound enzymes [32]. Some antifungal agents inhibit fungal growth by interrupting ergosterol biosynthesis through binding to ergosterol in membranes. This damages the integrity and function of membrane-bound proteins and disturbs osmosis, fungal growth and proliferation [32]. In our study, natural cinnamaldehyde at $25-50 \mu \mathrm{g} / \mathrm{mL}$ caused a mild reduction in ergosterol production and significantly inhibited ergosterol production in A. ochraceus at $75-200 \mu \mathrm{g} / \mathrm{mL}$, with inhibition ranging from $80 \%$ to $100 \%$. Various research groups have reported the oscillations in ergosterol biosynthesis [20,28,33]. Yamamoto-Ribeiro et al. (2013) [20] found that Zingiber officinale essential oil increases ergosterol biosynthesis of $F$. vertcillioides at $100 \mu \mathrm{g} / \mathrm{mL}$ compared with the control group and reduces or completely inhibits ergosterol biosynthesis at higher concentrations. Lucini et al. (2006) [33] found that monoterpenes at low concentrations lead to lipid peroxidation in fungi, inducing an adaptive response and reprogramming genomic expression to protect the cell wall structure, and consequently increase ergosterol biosynthesis. Dabolena et al. (2008) [29] found that limonene, menthol, menthone, and thymol at $75 \mu \mathrm{g} / \mathrm{mL}$ could increase ergosterol production by $F$. verticillioides.

In general, natural cinnamaldehyde and eugenol slightly inhibited biosynthesis of ergosterol and OTA at lower concentrations and significantly or completely inhibited biosynthesis at higher concentrations. The reductions of OTA production caused by cinnamaldehyde and eugenol at $25-100 \mu \mathrm{g} / \mathrm{mL}$ were positively correlated with EOs-induced ergosterol inhibition. Therefore, the decrease in OTA production was proportional to the decrease in fungal biomass at some levels. This result was similar with the findings of Yamamoto-Ribeiro et al. (2013) [20] and Dambolena et al. (2010) [34]. Their studies reported that essential oils from Zingiber officinale, Ocimum basilicum L. and Ocimum gratissimum L. inhibited fumonisin production by $F$. verticillioides and the inhibition was proportional to the decrease in fungal biomass.

However, citral showed a different effect than natural cinnamaldehyde and eugenol. Citral at $75-150 \mu \mathrm{g} / \mathrm{mL}$ completely inhibited OTA production but not ergosterol biosynthesis. This result suggested that the decrease in OTA production induced by citral was not due to the decrease in fungal biomass but might be due to suppression of transcription of OTA biosynthesis genes. The polyketide synthase gene ( $p k s$ gene) is responsible for the synthesis of the polyketide dihydroisocoumarin and involved in the first steps of the OTA biosynthetic pathway. Real-time quantify PCR (qPCR) analysis confirmed that the transcription of $p k s$ gene was completely inhibited by $75-150 \mu \mathrm{g} / \mathrm{mL}$ of citral. A similar inhibition of OTA production was observed with higher concentration of eugenol. At lower concentrations $(25-100 \mu \mathrm{g} / \mathrm{mL})$, the decrease in OTA production by eugenol was proportional to the decrease in fungal biomass. However, at $150-200 \mu \mathrm{g} / \mathrm{mL}$ OTA production was completely inhibited by eugenol but ergosterol production was not fully inhibited. This result suggested that inhibition of OTA required a lower oil concentration of EO than the inhibition of fungal growth. This finding agrees with results from Passone et al. (2012) [23], who reported complete inhibition of OTA production by Aspergillus niger RCP42 at $\geq 1000 \mu \mathrm{L} / \mathrm{L}$ of clove oil, whose main component is eugenol, while total fungal growth inhibition did not occur at $3000 \mu \mathrm{L} / \mathrm{L}$ at $a_{\mathrm{w}} 0.98$. Complete inhibition of OTA production by Aspergillus carbonarius RCP203 occurred at $\geq 1000 \mu \mathrm{L} / \mathrm{L}$ of clove oil, while total fungal growth inhibition did not occur at $3000 \mu \mathrm{L} / \mathrm{L}$ at $a_{\mathrm{w}} 0.93$. Murthy et al. (2009) [35] found that fungal growth and OTA production decreased progressively with increases in Ajowan ethanolic extract (AEE) concentration. At $250 \mu \mathrm{L} / \mathrm{mL}$, they could see fungal growth and OTA production being inhibited. However, the inhibition towards fungal growth and OTA biosynthesis was not linear. At 50 and $150 \mu \mathrm{L} / \mathrm{g}$ of AEE, inhibition of OTA production was higher than inhibition of fungal growth. Jayashree and Subramanyam (1999) [36] found that eugenol up to $0.75 \mathrm{mmol} / \mathrm{L}$ inhibited aflatoxin production with no significant effect on Aspergillus parasiticus growth. Furthermore, they found that eugenol inhibited the lipid peroxidation in aflatoxin production with no significant inhibition of growth or primary metabolism. However, an inverse correlation was shown by Pereira et al. (2006) [37] who observed that clove oil could completely inhibit the mycelial growth of $A$. ochraceus, but no significant affect in antiochratoxigenic activity.

This is the first study to show that $A$. ochraceus can convert cinnamaldehyde to cinnamic alcohol at $\leq 12 \mathrm{~h}$, and cinnamic alcohol was further degraded and no new metabolites were detected by RP-HPLC. The degradation might be due to Aspergillus genus has several enzymes such as alcohol dehydrogenase and aldehyde reductase that catalyze cinnamaldehyde to cinnamic alcohol [38,39]. Similar result was obtained by Vsivalingam et al. (2013) [40], who firstly found that E. coli O157:H7 could convert cinnamaldehyde to cinnamic alcohol by alcohol dehydrogenase and 2,5-diketo-D-gluconate reductase A.

\section{Conclusions}

The inhibitory effect of 10 essential oils on A. ochraceus growth was tested with fumigation and contact assays. Natural cinnamaldehyde proved to be the most effective against $A$. ochraceus, followed by cinnamon oil, synthetic cinnamaldehyde, citral, $L$. citrate oil, eugenol and peppermint oil. Headspace volatile assays showed higher inhibition than contact assays with exception of eugenol and peppermint oil. SEM of $A$. ochraceus cells fumigated with natural cinnamaldehyde, citral and eugenol showed alteration in the morphology of the hyphae which appeared collapsed, and abnormal branching of hyphae in apical region and loss of linearity. The inhibitory effects of natural cinnamaldehyde, citral and eugenol on ergosterol biosynthesis and OTA production indicated that natural cinnamaldehyde had a higher antifungal activity than citral and eugenol. However, natural cinnamaldehyde had a lower antiochratoxigenic effects than citral and eugenol. These results suggested that the inhibition of OTA production by natural cinnamaldehyde was mainly due to a decrease in fungal biomass. However, in addition to antifungal activity, citral and eugenol could significantly inhibit the OTA biosynthesis pathway of $A$. ochraceus.

\section{Acknowledgments}

We are sincerely grateful to the other members in the Y. L. group at Institute of Agro-Products Processing and Sciences Technology that offered helpful suggestions for the analysis. 


\section{Author Contributions}

Conceived and designed the experiments: YL FGX. Performed the experiments: HJH FGX JNS XL YJZ LZ YW. Analyzed the data: HJH

\section{References}

1. Pardo E, Marín S, Ramos A, Sanchis V (2006) Ecophysiology of ochratoxigenic Aspergillus ochraceus and Penicillium verrucosum isolates. Predictive models for fungal spoilage prevention-a review. Food Addit Contam A 23: 398-410.

2. Hocking AD, Leong SL, Kazi BA, Emmett RW, Scott ES (2007) Fungi and mycotoxins in vineyards and grape products. Int J Food Microbiol 119: 84-88.

3. Bayman P, Baker JL (2006) Ochratoxins: a global perspective. Mycopathologia 162: 215-223.

4. Huffman J, Gerber R, Du L (2010) Recent advancements in the biosynthetic mechanisms for polyketide-derived mycotoxins. Biopolymers 93: 764-776.

5. Sokolić-Mihalak D, Frece J, Slavica A, Delaš F, Pavlović H, et al. (2012) The effects of wild thyme (Thymus Serpyllum L.) essential oil components against ochratoxin-producing Aspergilli. Arch Indust Hygiene Toxicol 63: 457-462.

6. Reddy K, Salleh B, Saad B, Abbas H, Abel C, et al. (2010) An overview of mycotoxin contamination in foods and its implications for human health. Toxin Rev 29: 3-26.

7. Čvek D, Markov K, Frece J, Dragičević T, Majica M, et al. (2010) Growth inhibition of Aspergillus ochraceus ZMPBF 318 and Penicillium expansum ZMPBF 565 by four essential oils. Arch Indust Hygiene Toxicol 61: 191-196.

8. O'Brien E, Dietrich DR (2005) Ochratoxin A: the continuing enigma. Crit Rev Toxicol 35: 33-60.

9. Pfohl-Leszkowicz A, Manderville RA (2007) Ochratoxin A: An overview on toxicity and carcinogenicity in animals and humans. Mol Nutr Food Res 51: 6199.

10. Chen PJ, Moore T, Nesnow S (2008) Cytotoxic effects of propiconazole and its metabolites in mouse and human hepatoma cells and primary mouse hepatocytes. Toxicol In Vitro 22: 1476-1483.

11. Al-Omair A, Helaleh MIH (2004) Selected-Ion storage GC-MS analysis of polycyclic aromatic hydrocarbons in palm dates and tuna fish. Chromatographia 59: 715-719.

12. Baird RE, Brenneman TB, Bell DK, Murphy AP (1991) The effects of the fungicide propiconazole (Tilt) on the groundnut shell mycobiota. Mycol Res 95: 571-576.

13. Chilvers MI, Hay FS, Hills J, Dennis JJC, Wilson CR (2006) Influence of benzimidazole fungicides on incidence of Botrytis allii infection of onion leaves and subsequent incidence of onion neck rot in storage in Tasmania, Australia. Aust J Exp Agr 46: 1661-1664.

14. Simko P (2005) Factors affecting elimination of polycyclic aromatic hydrocarbons from smoked meat foods and liquid smoke flavorings. Mol Nutr Food Res 49: 637-647.

15. Isaac $\mathrm{S}$ (1999) What is the mode of action of fungicides and how do fungi develop resistance? Mycologist 13: 38-39.

16. Thompson D (1989) Fungitoxic activity of essential oil components on food storage fungi. Mycologia 81: 151-153.

17. Tian J, Ban X, Zeng H, He J, Huang B, et al. (2011) Chemical composition and antifungal activity of essential oil from Cicuta virosa L. var. latisecta Celak. Int J Food Microbiol 145: 464-470.

18. Patil JR, Jayaprakasha GK, Chidambara Murthy KN, Tichy SE, Chetti MB, et al. (2009) Apoptosis-mediated proliferation inhibition of human colon cancer cells by volatile principles of Citrus aurantifolia. Food Chem 114: 1351-1358.

19. Velluti A, Sanchis V, Ramos AJ, Marín S (2004) Effect of essential oils of cinnamon, clove, lemon grass, oregano and palmarosa on growth of and fumonisin $\mathrm{B}_{1}$ production by Fusarium verticillioides in maize. J Sci Food Agr 84: 1141-1146.

20. Yamamoto-Ribeiro MMG, Grespan R, Kohiyama CY, Ferreira FD, Mossini SAG, et al. (2013) Effect of Zingiber officinale essential oil on Fusarium verticillioides and fumonisin production. Food Chem 141: 3147-3152.

21. Bluma RV, Etcheverry MG (2008) Application of essential oils in maize grain: Impact on Aspergillus section Flavi growth parameters and aflatoxin accumulation. Food Microbiol 25: 324-334.
FGX. Contributed reagents/materials/analysis tools: HJH FGX. Contributed to the writing of the manuscript: FGX HJH YL.

22. Passone MA, Girardi NS, Etcheverry M (2012) Evaluation of the control ability of five essential oils against Aspergillus section Nigri growth and ochratoxin A accumulation in peanut meal extract agar conditioned at different water activities levels. Int J Food Microbiol 159: 198-206.

23. Avila-Sosa R, Palou E, Jiménez Munguía MT, Nevárez-Moorillón GV, Navarro Cruz AR, et al. (2012) Antifungal activity by vapor contact of essential oils added to amaranth, chitosan, or starch edible films. Int J Food Microbiol 153: 66-72.

24. Soliman KM, Badeaa RI (2002) Effect of oil extracted from some medicinal plants on different mycotoxigenic fungi. Food Chem Toxicol 40: 1669-1675.

25. Xing F, Hua H, Selvaraj JN, Zhao Y, Zhou L, et al. (2014) Growth inhibition and morphological alterations of Fusarium verticillioides by cinnamon oil and cinnamaldehyde. Food Control 46: 343-350.

26. Kocić-Tanackov S, Dimić G, Tanackov I, Pejin D, Mojović L, et al. (2012) The inhibitory effect of oregano extract on the growth of Aspergillus spp. and on sterigmatocystin biosynthesis. LWT-Food Sci Technol 49: 14-20.

27. Silva RR, Corso GR, Matheus DR (2010) Effect of culture conditions on the biomass determination by ergosterol of Lentinus crinitus and Psilocybe castanella. World J Microbiol Biotechnol 26: 841-846.

28. Scudamore KA, MacDonald SJ (1998) A collaborative study of an HPLC method for determination of ochratoxin $\mathrm{A}$ in wheat using immunoaflinity column clean-up. Food Addit Contam 15: 401-410.

29. Dambolena JS, López AG, Cánepa MC, Theumer MG, Zygadlo JA, et al (2008) Inhibitory effect of cyclic terpenes (limonene, menthol, menthone and thymol) on Fusarium verticillioides MRC 826 growth and fumonisin $\mathrm{B}_{1}$ biosynthesis. Toxicon 51: 37-44.

30. Fandohan P, Gbenou JD, Gnonlonfin B, Hell K, Marasas WF, et al. (2004) Effect of essential oils on the growth of Fusarium verticillioides and fumonisin contamination in corn. J Agric Food Chem 52: 6824-6829.

31. Tolouee M, Alinezhad S, Saberi R, Eslamifar A, Zad SJ, et al. (2010) Effect of Matricaria chamomilla $\mathrm{L}$. flower essential oil on the growth and ultrastructure of Aspergillus niger van Tieghem. Int J Food Microbiol 139: 127-133.

32. Bendaha H, Yu L, Touzani R, Souane R, Giaever G, et al. (2011) New azole antifungal agents with novel modes of action: synthesis and biological studies of new tridentate ligands based on pyrazole and triazole. Eur J Med Chem 46: 4117-4124.

33. Lucini EI, Zunino MP, López ML, Zygadlo JA (2006) Effect of monoterpenes on lipid composition and sclerotial development of Sclerotium cepivorum Berk. J Phytopathol 154: 441-446.

34. Dambolena JS, Zunino MP, López AG, Rubinstein HR, Zygadlo JA, et al. (2010) Essential oils composition of Ocimum basilicum L. and Ocimum gratissimum L. from Kenya and their inhibitory effects on growth and fumonisin production by Fusarium verticillioides. Innov Food Sci Emerg 11: 410-414.

35. Murthy PS, Borse BB, Khanum H, Srinivas P (2009) Inhibitory effects of Ajwain (Trachyspermum ammi) ethanolic extract on $A$. ochraceus growth and ochratoxin production. Turk J Biol 33: 211-217.

36. Jayashree T, Subramanyam C (1999) Antiaflatoxigenic activity of eugenol is due to inhibition of lipid peroxidation. Lett Appl Microbiol 28: 179-183.

37. Pereira MC, Chalfoun SM, Pimenta CJ, Angélico CL, Maciel WP (2006) Spices, fungi mycelial development and ochratoxin A production. Sci Res Essay 1: 3842.

38. Díaz E, Ferrández A, Prieto MA, García JL (2001) Biodegradation of aromatic compounds by Escherichia coli. Microbiol Mol Biol Rev 65: 523-569.

39. Grahl N, Puttikamonkul S, Macdonald JM, Gamcsik MP, Ngo LY, et al. (2011) In vivo hypoxia and a fungal alcohol dehydrogenase influence the pathogenesis of invasive pulmonary aspergillosis. PLoS Pathog 7: e1002145.

40. Visvalingam J, Hernandez-Doria JD, Holley RA (2013) Examination of the genome-wide transcriptional response of Escherichia coli $\mathrm{O} 157: \mathrm{H} 7$ to cinnamaldehyde exposure. Appl Environ Microbiol 79: 942-950. 